\title{
Correction: Suppression of CD300A inhibits the growth of diffuse large B-cell lymphoma
}

\section{Lei Jiang, Yulian Xu, Xinli Zeng, Jianchen Fang, Herbert C. Morse III, Jeff X. Zhou}

Copyright: Jiang et al. This is an open-access article distributed under the terms of the Creative Commons Attribution License (CC-BY), which permits unrestricted use, distribution, and reproduction in any medium, provided the original author and source are credited.

Present: Due to an error during manuscript preparation, the primer sequences for CD300A included in the published paper are incorrect.

Correct: The proper primer sequences are shown below. The authors sincerely apologize for this oversight.

Original article: Oncotarget. 2015; 6:31191-202. doi: 10.18632/oncotarget.5152

\section{Quantitative real-time PCR (qRT-PCR)}

The levels of CD300A mRNA was determined using qRT-PCR as previously described [26]. Briefly, total RNA was extracted using Trizol reagent (Invitrogen, Shanghai, China) according to the manufacturer's instructions. cDNA was prepared using a reverse transcription kit (Thermo Scientific, Shanghai, China). qRT-PCR was performed using SYBR Green PCR master mix on a LightCycler 480 system (Roche, Shanghai, China). All samples were run in triplicate. The levels of CD300A expression were normalized to that of glyceraldehyde-3-phosphate dehydrogenase (GAPDH). The primers used for CD300A were 5'-GGTCCCAGCATCAACGTCAA-3' (forward) and 5'-CCCACTGCAAACAGGGTAGT-3' (reverse), and for GAPDH were 5'-CGACCACTTTGTCAAGCTCA-3' (forward) and 5'-CCCTGTTGCTGTAGCCAAAT-3' (reverse). 